\title{
XPS spectra
}<smiles></smiles>

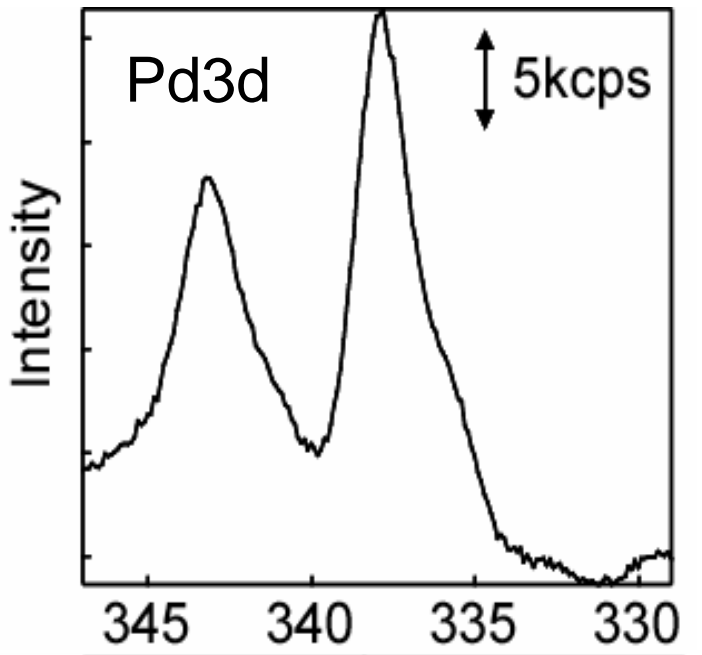

$\mathrm{PdCl}_{2}$ treatment
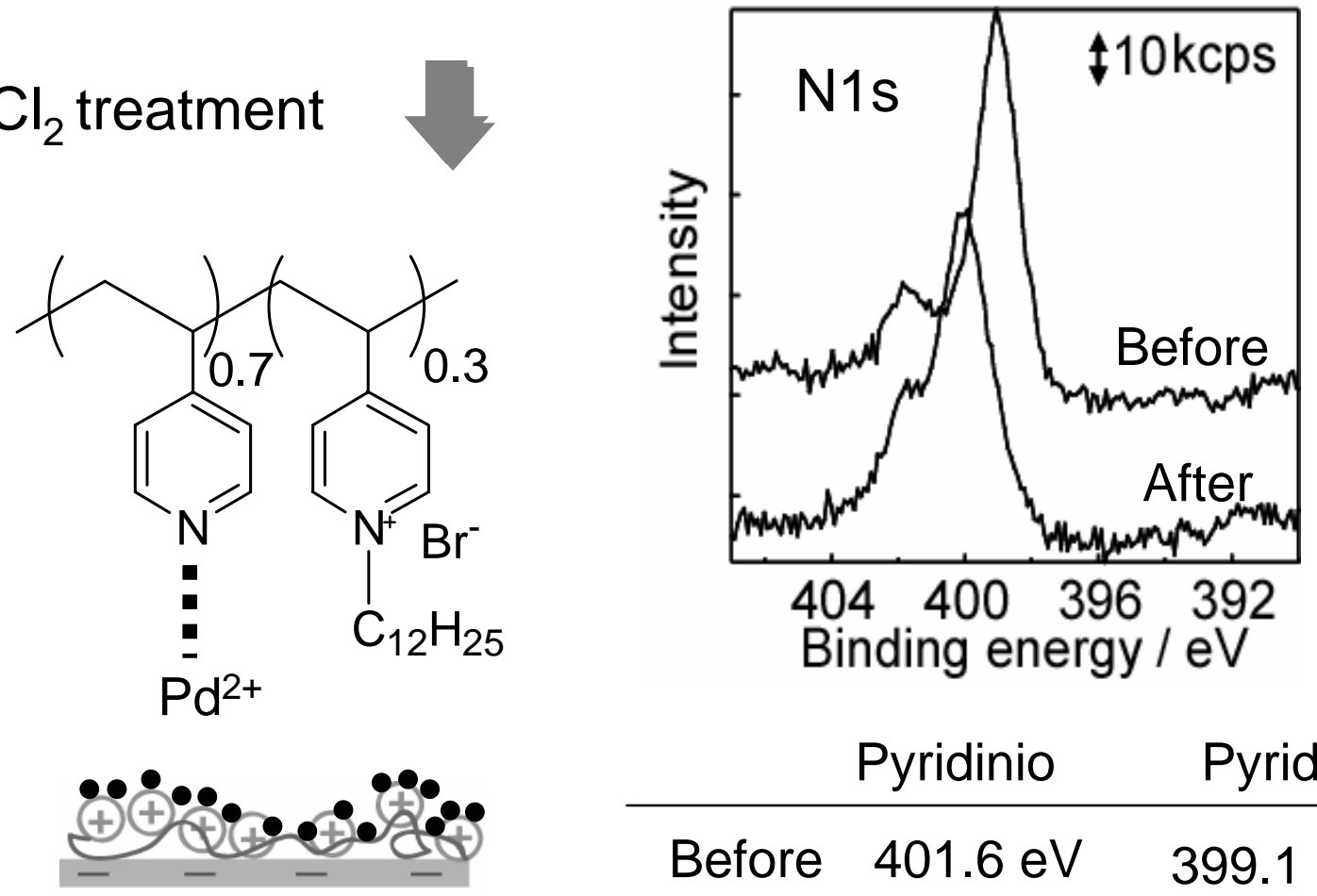

Pyridinio

Pyridyl

Before $\quad 401.6 \mathrm{eV} \quad 399.1 \mathrm{eV}$

After $\quad 401.6 \mathrm{eV} \quad 399.9 \mathrm{eV}$

Support 1 XPS spectra of a film of poly(4-vinyl pyridine-co-1-dodecyl4-vinylpyridinium bromide) on a silicon wafer before and after its immersion in the acidic $\mathrm{PdCl}_{2}$ solution. Before the immersion, the pyridyl and pyridinio moiety gave an N 1s BE at 399.1 and $401.6 \mathrm{eV}$, respectively. After the immersion, the $\mathrm{BE}$ of the pyridyl moiety was only shifted to $399.9 \mathrm{eV}$ and a $\mathrm{Pd} 3 \mathrm{~d}_{5 / 2}$ BE appeared at $338.1 \mathrm{eV}$. 